\title{
The Stratigraphical Changes of the Skulls from Moyoro Shell Heap
}

\author{
By \\ Shoichi Ito \\ Department of Anatomy. School of Medicine, \\ Hokkaido University, Sapporo
}

The Moyoro Shell Heap is situated at Abashiri City in the northern part of Hokkaido which faces Okhotsk Sea Coast. A large number of cultural remains such as earthen potteries, stone-implements, bone-implements and also the human bones were excavated and we are calling the race "The Moyoro Shell Heap Man". Judging from the cultural remains, the Moyoro Shell Heap could be presumed to be 700-1000 years of age.

In the Moyoro Shell Heap the strata could be distinctly classified into three, namely, the first superficial black earth stratum, the second shell stratum and the third natural sand stratum, under which lay the clay stratum. The superficial stratum was about $30-40 \mathrm{~cm}$, the shell stratum about $15-90 \mathrm{~cm}$, and the sand stratum about $100-150 \mathrm{~cm}$ in thickness. The human bones were found in each stratum and on the general characteristics of the skulls has

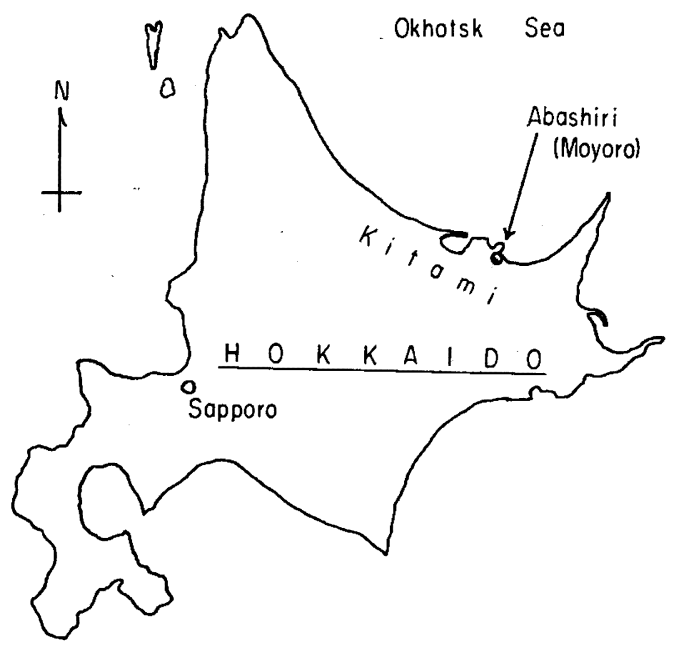


the author already made a speach at the 53th Japanese Anatomical Congress (1948), and Prof. S. Kodam a has stated them in his book "The Moyoro Shell Heap" (1948). According to further obser vations, the skulls were considered to have slight, morphological differences in accordance with the kind of the stratum, and so an attempt was made by the author to classify the human bones according to the stratum and to investigate each characteristic. In the present paper the author is going to report the results of the measurements of the skulls.

\section{The Classification of the Skulls}

Based on the below, the author classified the skulls from Moyoro Shell Heap into three groups, that is, the firtst group (Moyoro I), the second group (Moyoro II) and the third group (Moyoro III). The first group consisted of all the skulls from the sand stratum, which lay deeper than the shell stratum and most of the skulls from the lower border of the shell stratum. The first group was thought to be the race which formed the Moyoro Shell Heap, that is to say, the Moyoro Shell Heap Man in the earliest days. Accordingly, the author regards this group as the Moyoro Shell Heap Man with the typical physical characteristics.

The second group consisted of some skulls from the lower border of the shell stratum and all the skulls from the shell stratum. Out of those which came from the lower margin of the shell stratum, there were some cases with the stirred traces in the shell stratum over the human bones. As these cases were thought to be buried in process of the formation of the Moyoro Shell Heap, these cases as well as those from the shell stratum failed to be as old as the first group.

The third group consisted of those which were excavated from the superficial stratum lying over the shell stratum and this group belonged undoubtedly to the days after the period of the formation of the Moyoro Shell Heap.

As for the burial form, all cases of the first and the second group took the squatted position lying on their back with the upper and lower lims strongly bent over the body, while the third group took the stretched position lying on their back, which was the same way with the modern Ainu.

Approximately three hundred cases were collected and out of them 87 skulls of the adult male and female worth measuring were 
investigated with the exception of the corrode, broken, and younger cases. In comparison with the Moyoro Shell Heap Man the Ainu skulls in the Kitami Province were used.

\section{Metrical Observations}

\section{The Neurocranium}

1. The Glabello-Occipital Length (Marti n, No. $1^{*}$ ) (Table 1) in the male of the third group and the Kitami Ainu is considered to have a slightly increasing tendency in comparison with that of the first and the second group, but no remarkable difference is observed as far as the length in the four female groups is concerned. However, the Maximum Breadth (Martin, No. 8) (Table 2) in the male is the largest of all in the first group, larger in the second and the third group and the smallest in the Kitami Ainu, with a significant difference between the first group and the Kitami Ainu. The same kind of the tendency will be found also in the case of the female. The Basion-Bregma Height (Martin, No. 17) (Table 3 ) in the case of the third group and the Kitami Ainu seems to have a decreasing tendency compared to that of the first and the second group.

Table 1. Glabello-Occipital Length.

\begin{tabular}{|c|c|c|c|c|c|}
\hline & \multicolumn{2}{|r|}{$\hat{\delta}$} & \multicolumn{2}{|r|}{ 우 } \\
\hline & & $\mathrm{n}$ & $\mathrm{M} \pm \mathrm{E}(\mathrm{M})$ & $\mathrm{n}$ & $\mathrm{M} \pm \mathrm{E}(\mathrm{M})$ \\
\hline Moyoro & I & 14 & 185. $0_{ \pm 0.31}$ & 5 & 178. $8_{ \pm 1.77}$ \\
\hline$"$ & II & 12 & 184. $3_{ \pm 1.03}$ & 9 & 179. $7_{ \pm 1.00}$ \\
\hline , & IIII & 8 & $192.3_{ \pm 1.04}$ & 2 & 178.5 \\
\hline Kitami- & Iinu & 31 & $189.5_{ \pm 0.66}$ & 21 & $180.8_{ \pm 0.84}$ \\
\hline
\end{tabular}

Table 3. Basion-Bregma Height.

\begin{tabular}{|c|c|c|c|c|c|}
\hline & \multicolumn{2}{|r|}{$\hat{\delta}$} & \multicolumn{2}{|r|}{ 우 } \\
\hline & & $\mathrm{n}$ & $\mathrm{M} \pm \mathrm{E}(\mathrm{M})$ & $\mathrm{n}$ & $\mathbf{M} \pm \mathrm{E}(\mathbf{M})$ \\
\hline Moyoro & $I$ & 13 & $141.2_{ \pm 1.15}$ & 3 & 134.0 \\
\hline$"$ & II & 9 & $141.6_{ \pm 1.33}$ & 7 & $136.3_{ \pm 0.86}$ \\
\hline$"$ & III & 7 & $138.4_{ \pm 1.24}$ & 0 & - \\
\hline Kitami- & Ainu & 28 & $137.6_{ \pm 0.58}$ & 21 & $133.4_{ \pm 0.64}$ \\
\hline
\end{tabular}

Table 2. Maximum Breadth.

\begin{tabular}{|c|c|c|c|c|}
\hline & \multicolumn{2}{|r|}{ 今 } & \multicolumn{2}{|r|}{ 우 } \\
\hline & $\mathrm{n}$ & $\mathrm{M} \pm \mathrm{E}(\mathrm{M})$ & $\mathrm{n}$ & $M \pm E(M)$ \\
\hline Moyoro I & 14 & $148.6_{ \pm 0.78}$ & 4 & 141.8 \\
\hline II & 11 & $141.6_{ \pm 1.12}$ & 9 & $137.4_{ \pm 0.83}$ \\
\hline III & 8 & $111.6_{ \pm 1.15}$ & 2 & 135.0 \\
\hline Kitami-Ainu & 31 & $139.9_{ \pm 0.59}$ & 21 & $137.3_{ \pm 0.35}$ \\
\hline
\end{tabular}

Table 4. Cranial Index.

\begin{tabular}{|c|c|c|c|c|c|}
\hline & \multicolumn{2}{|r|}{ 今 } & \multicolumn{2}{|r|}{ 우 } \\
\hline & & $\mathrm{n}$ & $\mathrm{M} \pm \mathrm{E}(\mathrm{M})$ & $\mathrm{n}$ & $\mathrm{M} \pm \mathrm{E}(\mathrm{M})$ \\
\hline Moyoro & $I$ & 14 & $80.4_{ \pm 0.66}$ & 4 & 80.0 \\
\hline " & II & 11 & $77.2_{ \pm 0.61}$ & 10 & $76.5_{ \pm 0.33}$ \\
\hline$"$ & III & 7 & 73. $9_{ \pm 0.43}$ & 2 & 75.7 \\
\hline Kitami- & Ainu & 31 & 74. $0_{ \pm 0.29}$ & 21 & 75. $9_{ \pm 0.31}$ \\
\hline
\end{tabular}

* The figure which follows $\mathrm{Mar} t$ in is the number for the measurements according to R. Marti n's "Lehrbuch der Anthropologie”, vol. 2 (1928). 
As so-called three main measurements show the fluctuations as described in the above, the calculated indices also make the following differences. The Cranial Index (Marti $\mathrm{n}, 8 / 1$ ) (Table 4) in the male belongs to the bracycephalic type in the first group, to the mesocephalic type in the second group and to the dolichocephalic type in the third group and the Kitami Ainu. Almost the same fluctuations are found in the case of the female as in the case of the male. The Length-Height Index (Martin, 17/1) (Table 5) belongs to the hypsicephalic type in the first and the second group, while to the orthocephalic type in the third group and the Kitami Ainu. There exists a significant difference between the above mentioned two groups. The Breadth-Height Index (M a r t i n, 17/8) (Table 6) fails to show a remarkable difference between these four groups. Shown in the above, however, it is noteworthy that the breadth and the height show a gradual decrease toward the third group from the first group.

Table 5. Length-Height Index.

\begin{tabular}{|c|c|c|c|c|c|}
\hline & \multicolumn{2}{|r|}{$\hat{\delta}$} & \multicolumn{2}{|r|}{ 우 } \\
\hline & & $\mathrm{n}$ & $\mathrm{M} \pm \mathrm{E}(\mathrm{M})$ & $\mathrm{n}$ & $\mathrm{M} \pm \mathrm{E}(\mathrm{M})$ \\
\hline Moyoro & I & 13 & $76.4_{ \pm 0.66}$ & 3 & 77.1 \\
\hline " & II & 9 & $77.5_{ \pm 0.69}$ & 7. & $75.6_{ \pm 0.48}$ \\
\hline " & III & 7 & $72.2_{ \pm 0.62}$ & 0 & - \\
\hline Kitami- & Ainu & 28 & $72.8_{ \pm 0.29}$ & 21 & $73.7_{ \pm 0.35}$ \\
\hline
\end{tabular}

Table 6. Breadth-Height Index.

\begin{tabular}{|c|c|c|c|c|}
\hline & \multicolumn{2}{|r|}{$\delta$} & \multicolumn{2}{|r|}{ 우 } \\
\hline & $\mathrm{n}$ & $M \pm E(M)$ & $\mathrm{n}$ & $M \pm E(M)$ \\
\hline Moyoro I & 13 & $95.7_{ \pm 0 . .55}$ & 3 & 95.8 \\
\hline II & 9 & $100.4_{ \pm 0.95}$ & 7 & 98. $9_{ \pm 052}$ \\
\hline III & 7 & $98.0_{ \pm 0.70}$ & 0 & - \\
\hline Kitami-Ainu & 28 & $98.8_{ \pm 0.52}$ & 21 & $97.3_{ \pm 0.41}$ \\
\hline
\end{tabular}

From the point of view of morphology the following points are remarkable in the execution of the above mentioned measurements. The glabella which works as the basic point in measuring the Glabello-Occipital Length is in the third group and the Kitami Ainu prominent and the nasion shortly under the glabella is strongly depressed, so that consequently the profile shows uneven curve, while in the first group the glabella is less prominent and the nasion less depressed, so that consequently the profile shows a smooth and nearly flat curve. Further, taking an anterior view of the neurocranium, the contour lines of the first group exhibit a tendency to show a roof shape with the risen parietal bones in the median line where the sagittal suture is, while those of the third group and the Kitami Ainu to show a dome shape with the flat parietal bones in the median line.

2. Taking a view of the base of the skull, as for the Cranial 
Base Length (M a r ti n, No. 5) (Table 7), no significant differences were observed between four groups as shown in the table. However, the Intermastoideal Breadth (Martin, No. 13) (Table 8) is the longest of all in the first group, longer in the second group, and the shortest of all in the third group and the Kitami Ainu, with a remarkable difference between the firts group and the latter two. The above mentioned difference is parallel to that of the Maximum Breadth. Consequently, the Cranial Base Index (M a r tin, 5/13) (Table 9) is the smallest in the first group, comparatively larger in the second group and the largest of all in the third group and the Kitami Ainu. There can be observed the significant difference between the first group and the latter two.

3. The Circumference (Martin, No. 23) (Table 10) is the largest in the first group, slightly less larger in the second and the third group, and the smallest in the Kitami Ainu. In general, out of all races the Ainu is one of those with a large circumference, and so the Moyoro Shell Heap Man would be thought to have a much larger circumference.

Table 7. Cranial Base Length.

\begin{tabular}{|c|c|c|c|c|c|}
\hline & \multicolumn{2}{|r|}{$\hat{\delta}$} & \multicolumn{2}{|r|}{ 우 } \\
\hline & & $\mathbf{n}$ & $\mathbf{M} \pm \mathrm{E}(\mathbf{M})$ & $\mathrm{n}$ & $M \pm E(M)$ \\
\hline Moyoro & I & 13 & $106.8_{ \pm 0.78}$ & & 102.5 \\
\hline ", & II & 9 & 106. $0_{ \pm 0.85}$ & & 104. $0_{ \pm 1.11}$ \\
\hline " & II & 7 & $108.6_{ \pm 1.10}$ & 0 & - \\
\hline Kitami- & Ainu & 27 & $107.1_{ \pm 0.57}$ & 21 & $101.2_{ \pm 053}$ \\
\hline
\end{tabular}

Table 9. Cranial Base Index.

\begin{tabular}{|c|c|c|c|c|}
\hline & \multicolumn{2}{|r|}{$\hat{\delta}$} & \multicolumn{2}{|r|}{ 우 } \\
\hline & $\mathbf{n}$ & $\mathrm{M} \pm \mathrm{E}(\mathrm{M})$ & $\mathrm{n}$ & $M \pm E(M)$ \\
\hline Moyoro I & 12 & $95.3_{ \pm 0.94}$ & 4 & 97.5 \\
\hline II & 8 & $99.5_{ \pm 0.77}$ & 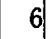 & $101.2_{ \pm 1.43}$ \\
\hline III & 7 & $101.8_{ \pm 0.91}$ & 0 & - \\
\hline Kitami-Ainu & 27 & $102.7_{ \pm 056}$ & 21 & $102.4_{ \pm 0.65}$ \\
\hline
\end{tabular}

Table 8. Intermastoideal Breadth.

\begin{tabular}{|c|c|c|c|c|}
\hline & \multicolumn{2}{|r|}{$\hat{o}$} & \multicolumn{2}{|r|}{ 우 } \\
\hline & $\mathrm{n}$ & $\mathbf{M} \pm \mathrm{E}(\mathrm{M})$ & $\mathrm{n}$ & $\mathbf{M} \pm \mathrm{E}(\mathrm{M})$ \\
\hline Moyoro I & 13 & $113.2_{ \pm 0.74}$ & 5 & $105.0_{ \pm 1.06}$ \\
\hline II & 10 & $106,4_{ \pm 0.69}$ & 7 & $101.7_{ \pm 0.87}$ \\
\hline III & 7 & $104.9_{ \pm 0.96}$ & 0 & - \\
\hline Kitami-Ainu & 30 & 103. $9_{ \pm 0.54}$ & 21 & $99.3_{ \pm 0.58}$ \\
\hline
\end{tabular}

Table 10. Circumference.

\begin{tabular}{|rr|r|c|c|c|}
\hline & \multicolumn{2}{|c|}{$\hat{\delta}$} & \multicolumn{2}{|c|}{+} \\
\cline { 2 - 6 } & & $\mathbf{n}$ & $\mathrm{M} \pm \mathrm{E}(\mathrm{M})$ & $\mathrm{n}$ & $\mathrm{M} \pm \mathrm{E}(\mathrm{M})$ \\
\hline Moyoro & $\mathrm{I}$ & 14 & $540.5_{ \pm 1.62}$ & 4 & 515.0 \\
$"$ & II & 10 & $532.5_{ \pm 2.12}$ & 9 & $514.7_{ \pm 2.47}$ \\
$" \quad \mathrm{III}$ & 8 & $536.0_{ \pm 2.95}$ & 0 & - \\
\multicolumn{2}{|l|}{ Kitami-Ainu } & 30 & $529.8_{ \pm 1.63}$ & 20 & $510.5_{ \pm 1.81}$ \\
\hline
\end{tabular}

II. The Splanchnocranium

1. No remarkable difference is observed among the four groups in the male as well as in the female, as far as the Facial Length (Martin, No. 40) (Table 11) is concerned. However, in each case 
of the Total Facial Breadth (Marti n, No. 45) (Table 12), the Total Facial Height (Martin, No. 47) (Table 13) and the Upper Facial Height (M a r t i n, No. 48) (Table 14), the first group owns the lar it measurement, while the rest of all own less larger measurements than the above. Especially in the case of the Total Facial Height and the Upper Facial Height, there can be observed a significant difference between the first group and the third group and also between the first group and the Kitami Ainu. The Total Facial Index ( $M$ a r t i n, 47/45) (Table 15) indicates that the first group, the second group and the Kitami Ainu belong to the mesoprosope type, while the third group to the euryprosope type. However, no significant differences can be observed among these four groups. As far as the Upper Facial Index (Marti n, 48/45) (Table 16) is concerned, the third group and the Kitami Ainu seem to note a decreasing tendency in comparison with the first and the second group.

Table 11. Facial Length.

\begin{tabular}{|c|c|c|c|c|c|}
\hline & \multicolumn{2}{|r|}{$\hat{\delta}$} & \multicolumn{2}{|r|}{ 우 } \\
\hline & & $\mathrm{n}$ & $M \pm E(M)$ & $\mathrm{n}$ & $\mathrm{M} \pm \mathrm{E}(\mathrm{M})$ \\
\hline Moyoro & $I$ & 13 & 103. $3_{ \pm 1.25}$ & 4 & 100.8 \\
\hline$"$ & II & 5 & $106.8_{ \pm 0.98}$ & 4 & 103.3 \\
\hline , & III & 6 & $107.8_{ \pm 1.88}$ & 0 & - \\
\hline Kitami- & Ainu & 18 & $105.3_{ \pm 0.66}$ & 19 & $99.7_{ \pm 0.65}$ \\
\hline
\end{tabular}

Table 13. Total Facial Height.

\begin{tabular}{|c|c|c|c|c|c|}
\hline & \multicolumn{2}{|r|}{$\hat{o}$} & \multicolumn{2}{|r|}{ 우 } \\
\hline & & $\mathrm{n}$ & $\mathrm{M} \pm \mathrm{E}(\mathrm{M})$ & $\mathrm{n}$ & $\mathrm{M} \pm \mathrm{E}(\mathrm{M})$ \\
\hline Moyoro & $I$ & 9 & $129.0_{ \pm 1.25}$ & 4 & 116.8 \\
\hline , & II & 6 & $124.5_{ \pm 1.80}$ & 4 & 113.3 \\
\hline , & III & 5 & $118.4_{ \pm 1.52}$ & 0 & - \\
\hline Kitami- & Ainu & 22 & $119.7_{ \pm 0.98}$ & 16 & $110.6_{ \pm 0.67}$ \\
\hline
\end{tabular}

Table 15. Total Facial Index.

\begin{tabular}{|c|c|c|c|c|c|}
\hline & \multicolumn{2}{|r|}{$\hat{\delta}$} & \multicolumn{2}{|r|}{ 우 } \\
\hline & & $\mathrm{n}$ & $\mathrm{M} \pm \mathrm{E}(\mathrm{M})$ & $\mathrm{n}$ & $M \pm E(M)$ \\
\hline Moyoro & I & 9 & $87.1_{ \pm 0.98}$ & 2 & 87.0 \\
\hline , & II & 5 & $88.3_{ \pm 1.59}$ & 3 & 84.8 \\
\hline , & III & 5 & 83. $9_{ \pm 0.73}$ & 0 & - \\
\hline Kitami- & Ainu & 22 & $87.1_{ \pm 0.72}$ & 14 & $84.6_{ \pm 0.79}$ \\
\hline
\end{tabular}

Table 12. Total Facial Breadth.

\begin{tabular}{|c|c|c|c|c|c|}
\hline & \multicolumn{2}{|r|}{$\hat{\delta}$} & \multicolumn{2}{|r|}{ 우 } \\
\hline & & $\mathrm{n}$ & $\mathrm{M} \pm \mathrm{E}(\mathrm{M})$ & $\mathrm{n}$ & $\mathrm{M} \pm \mathrm{E}(\mathrm{M})$ \\
\hline Moyoro & $\mathrm{I}$ & 13 & $146.8_{ \pm 1.22}$ & 2 & 135.5 \\
\hline " & II & 5 & $139.4_{ \pm 1.14}$ & 5 & $130.0_{ \pm 1.25}$ \\
\hline$"$ & III & 6 & $141.8_{ \pm 1.66}$ & 0 & - \\
\hline Kitami- & inu & 27 & $137.4_{ \pm 0.77}$ & 17 & $131.1_{ \pm 0.65}$ \\
\hline
\end{tabular}

Table 14. Upper Facial Height.

\begin{tabular}{|c|c|c|c|c|c|}
\hline & \multicolumn{2}{|r|}{ 占 } & \multicolumn{2}{|r|}{ 우 } \\
\hline & & $\mathrm{n}$ & $M \pm E(M)$ & $\mathrm{n}$ & $M \pm E(M)$ \\
\hline Moyoro & I & 14 & $79.4_{ \pm 0.76}$ & 5 & $70.4_{ \pm 0}$ \\
\hline ,. & II & 8 & $75.6_{ \pm 0.61}$ & 5 & $67.4_{ \pm 1}$. \\
\hline , & III & 7 & $69.7_{ \pm 0.54}$ & 0 & - \\
\hline Kitami- & inu & 21 & $70.5_{ \pm 0.59}$ & 19 & $65.4_{ \pm 0 .}$ \\
\hline
\end{tabular}

Table 16. Upper Facial Index.

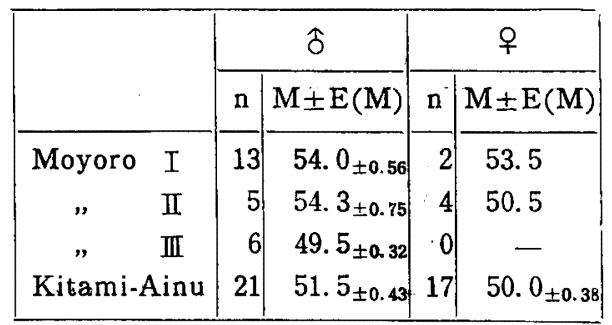


2. Taking a view of the orbit, in the Orbital Breadth (M a rti n, No. 51) (Table 17), no significant difference can be observed between the four groups. However, in the Orbital Height (M a rt i n, No. 52) (Table 18), the first group is larger than the other groups with the remarkable difference. Accordingly, in the Orbital Index (M a r t i n, 52/51) (Table 19), each of the four groups belongs to the mesoconche type, with the largest index in the first group, the larger in the second group and the smallest in the third group and the Kitami Ainu. The difference between the first group and the Kitami Ainu is significant. Examining the orbit morphologically, the first group possesses a square orbit which is more or less like a round shape, while the third group and the Kitami Ainu possess a quadrangular orbit.

3. With regard to the nasal part, no significant differences in

Table 17. Orbital Breadth (left).

\begin{tabular}{|c|c|c|c|c|c|}
\hline & \multicolumn{2}{|r|}{$\hat{\delta}$} & \multicolumn{2}{|r|}{ 우 } \\
\hline & & $\mathrm{n}$ & $\mathrm{M} \pm \mathrm{E}(\mathrm{M})$ & $\mathrm{n}$ & $\mathrm{M} \pm \mathrm{E}(\mathrm{M})$ \\
\hline Moyoro & $I$ & 14 & $44.4_{ \pm 0.41}$ & 5 & $42.4_{ \pm 0.36}$ \\
\hline ", & III & 9 & 42. $6_{ \pm 0.26}$ & 5 & $42.4_{ \pm 0.49}$ \\
\hline & III & 7 & $44.9_{ \pm 0.53}$ & 0 & - \\
\hline Kitami- & Ainu & 24 & 44. $7_{ \pm 0.25}$ & 18 & 43. $2_{ \pm 0.26}$ \\
\hline
\end{tabular}

Table 19. Orbital Index (left).

\begin{tabular}{|c|c|c|c|c|c|}
\hline & \multicolumn{2}{|r|}{$\widehat{\delta}$} & \multicolumn{2}{|r|}{ 우. } \\
\hline & & $\mathrm{n}$ & $\mathrm{M} \pm \mathrm{E}(\mathrm{M})$ & $\mathrm{n}$ & $\mathrm{M} \pm \mathrm{E}(\mathrm{M})$ \\
\hline Moyoro & I & 14 & $84.0_{ \pm 1.05}$ & 5 & $83.4_{ \pm 1.05}$ \\
\hline , & II & 9 & $80.4_{ \pm 1.01}$ & 5 & $80.1_{ \pm 1.37}$ \\
\hline ", & III & 7 & $77.9_{ \pm 1.17}$ & 0 & - \\
\hline Kitami- & Ainu & 24 & $77.6_{ \pm 0.58}$ & 18 & $80.5_{ \pm 0.68}$ \\
\hline
\end{tabular}

Table 21. Nasal Height.

\begin{tabular}{|rl|r|c|r|c|}
\hline & \multicolumn{2}{|c|}{$\delta$} & \multicolumn{2}{|c|}{ 우 } \\
\cline { 2 - 6 } & & $\mathrm{n}$ & $\mathrm{M} \pm \mathrm{E}(\mathrm{M})$ & $\mathrm{n}$ & $\mathrm{M} \pm \mathrm{E}(\mathrm{M})$ \\
\hline Moyoro & $\mathrm{I}$ & 14 & $56.1_{ \pm 0.34}$ & 5 & $50.8_{ \pm 0.40}$ \\
& II & 8 & $53.8_{ \pm 0.37}$ & 5 & $48.6_{ \pm 1.36}$ \\
" III & 7 & $50.9_{ \pm 0.32}$ & 0 & - \\
Ktiami-Ainu & 23 & $51.0_{ \pm 0.36}$ & 18 & $48.3_{ \pm 0.31}$ \\
\hline
\end{tabular}

Table 18. Orbital Height (left).

\begin{tabular}{|c|c|c|c|c|c|}
\hline & \multicolumn{2}{|r|}{$\hat{\delta}$} & \multicolumn{2}{|r|}{ 우 } \\
\hline & & $\mathrm{n}$ & $\mathrm{M} \pm \mathrm{E}(\mathrm{M})$ & $\mathrm{n}$ & $\mathrm{M} \pm \mathrm{E}(\mathrm{M})$ \\
\hline Moyoro & $I$ & 14 & $37.3_{ \pm 0.40}$ & 5 & $35.6_{ \pm 0.45}$ \\
\hline ", & II & 9 & $34.1_{ \pm 0.27}$ & 5 & $33.8_{ \pm 0.55}$ \\
\hline ,. & III & 7 . & $34.9_{ \pm 0.37}$ & 0 & - \\
\hline Kitami- & Ainu & 24 & $34.5_{ \pm 0.24}$ & 18 & $34.7_{ \pm 0.25}$ \\
\hline
\end{tabular}

Table 20. Nasal Breadth.

\begin{tabular}{|r|r|c|r|c|}
\hline & \multicolumn{2}{|c|}{ 交 } & \multicolumn{2}{|c|}{ 우 } \\
\cline { 2 - 5 } & $\mathrm{n}$ & $\mathrm{M} \pm \mathrm{E}(\mathrm{M})$ & $\mathrm{n}$ & $\mathrm{M} \pm \mathrm{E}(\mathrm{M})$ \\
\hline Moyoro I & 14 & $26.3_{ \pm 0.28}$ & 5 & $24.0_{ \pm 0.42}$ \\
Moyoro II & 7 & $26.4_{ \pm 0.47}$ & 4 & 25.8 \\
" III & 7 & $26.9_{ \pm 0.39}$ & 0 & - \\
Kitami-Ainu & 22 & $25.9_{ \pm 0.19}$ & 18 & $25.2_{ \pm 0.31}$ \\
\hline
\end{tabular}

Table 22. Nasal Index.

\begin{tabular}{|c|c|c|c|c|c|}
\hline & \multicolumn{2}{|r|}{$\hat{o}$} & \multicolumn{2}{|r|}{ 우 } \\
\hline & & $\mathrm{n}$ & $\mathrm{M} \pm \mathrm{E}(\mathrm{M})$ & $\mathrm{n}$ & $M \pm E(M)$ \\
\hline Moyoro & $I$ & 14 & 47. $0_{ \pm 0.65}$ & 4 & 47.5 \\
\hline " & II & 7 & $49.4_{ \pm 1.22}$ & 4 & 54.5 \\
\hline " & III & 7 & $53.1_{ \pm 0.87}$ & 0 & - \\
\hline Kitami- & Ainu & 22 & $51.1_{ \pm 0.34}$ & 18 & $52.5_{ \pm 0.79}$ \\
\hline
\end{tabular}


the Nasal Breadth (M a r t i n, No. 54) (Table 20) can be observed among the four groups, while in the Nasal Height ( $M$ a $r$ i $n$, No. 55) (Table 21) the first group has the largest measurement of ail the second group the larger, and the third group and the Kitam Ainu the smallest of all. Accordingly, in the Nasal Index ( $\mathrm{M}$ a $\mathrm{r}$ i i , 54/55) (Table 22) the first and the second group belong to the mesorrhine type, while the third group and the Kitami Ainu to the chamaerrhine type.

4. As regards of the alveolar part of the maxilla, the MaxilloAlveolar Length ( $\mathrm{M}$ a r t i n, No. 60) (Table 23) seems to be smaller in the first group, but actually no significant difference can be observed among the four groups. The Maxillo-Alveolar Breadth (M a r in, No. 61) (Table 24) is larger in the first and the second group, while smaller in the third group and the Kitami Ainu, with

Table 23. Maxillo-Alveolar Length.

\begin{tabular}{|c|c|c|c|c|c|}
\hline & \multicolumn{2}{|r|}{ 今 } & \multicolumn{2}{|r|}{ 우 } \\
\hline & & $\mathbf{n}$ & $\mathrm{M} \pm \mathrm{E}(\mathrm{M})$ & $\mathbf{n}$ & $\mathrm{M} \pm \mathrm{E}(\mathrm{M})$ \\
\hline Moyoro & $I$ & 10 & $54.8_{ \pm 0.66}$ & 6 & $51.7_{ \pm 0.94}$ \\
\hline " & II & 9 & $56.1_{ \pm 0.90}$ & 6 & $54.2_{ \pm 0.43}$ \\
\hline$"$ & III & 6 & $56.2_{ \pm 1.30}$ & 0 & - \\
\hline Kitami- & Ainu & 12 & $56.4_{ \pm 0.49}$ & 13 & 53. $6_{ \pm 0.46}$ \\
\hline
\end{tabular}

Table 25. Maxillo-Alveolar Index.

\begin{tabular}{|c|c|c|c|c|c|}
\hline & \multicolumn{2}{|r|}{$\delta$} & \multicolumn{2}{|r|}{ 우 } \\
\hline & & $\mathrm{n}$ & $\mathrm{M} \pm \mathrm{E}(\mathrm{M})$ & $\mathrm{n}$ & $\mathrm{M} \pm \mathrm{E}(\mathrm{M})$ \\
\hline Moyoro & $I$ & 10 & $125.6_{ \pm 1.34}$ & 6 & 123. $0_{ \pm 1.63}$ \\
\hline$"$ & III & 9 & $118.8_{ \pm 2.08}$ & 5 & $119.5_{ \pm 1.82}$ \\
\hline$"$ & III & 5 & $115.8_{ \pm 1.75}$ & 0 & 一 \\
\hline Kitami- & Ainu & 12 & $112.1_{ \pm 1.24}$ & 13 & $112.4_{ \pm 0.89}$ \\
\hline
\end{tabular}

Table 27. Bigonial Breadth.

\begin{tabular}{|c|c|c|c|c|c|}
\hline & \multicolumn{2}{|r|}{$\delta$} & \multicolumn{2}{|r|}{ 우 } \\
\hline & & $\mathrm{n}$ & $\mathrm{M} \pm \mathrm{E}(\mathrm{M})$ & $\mathrm{n}$ & $\mathrm{M} \pm \mathrm{E}(\mathrm{M})$ \\
\hline Moyoro & $I$ & 24 & $117.1_{ \pm 0.76}$ & 6 & $111.7_{ \pm 1.49}$ \\
\hline$"$ & II & 11 & $109.4_{ \pm 1.29}$ & 10 & 98. $6_{ \pm 1.30}$ \\
\hline " & III & 7 & $104.4_{ \pm 0.38}$ & 0 & - \\
\hline Kitami- & Ainu & 26 & $102.6_{ \pm 0.68}$ & 16 & $95.3_{ \pm 0.60}$ \\
\hline
\end{tabular}

Table 24. Maxillo-Alveolar Breadth.

\begin{tabular}{|c|c|c|c|c|c|}
\hline & \multicolumn{2}{|r|}{ } & \multicolumn{2}{|r|}{ 우 } \\
\hline & & $\mathrm{n}$ & $M \pm E(M)$ & $\mathrm{n}$ & $M \pm E(M)$ \\
\hline Moyoro & $I$ & 10 & $68.7_{ \pm 0.67}$ & 6 & $63.3_{ \pm 0.44}$ \\
\hline , & II & 9 & $66.4_{ \pm 0.79}$ & 5 & $64.4_{ \pm 0.86}$ \\
\hline " & III & 5 & $63.8_{ \pm 0.94}$ & 0 & - \\
\hline Kitami- & Ainu & 12 & $63.1_{ \pm 0.55}$ & 13 & $60.2_{ \pm 0.56}$ \\
\hline
\end{tabular}

Table 26. Intercondylar Breadth.

\begin{tabular}{|c|c|c|c|c|c|}
\hline & \multicolumn{2}{|r|}{$\delta$} & \multicolumn{2}{|r|}{ 우 } \\
\hline & & $\mathrm{n}$ & $\mathrm{M} \pm \mathrm{E}(\mathrm{M})$ & $\mathbf{n}$ & $M \pm E(M)$ \\
\hline Moyoro & $I$ & 22 & $132.4_{ \pm 0.87}$ & 5 & $127.0_{ \pm 1.6}$ \\
\hline " & II & 8 & $124.1_{ \pm 1.80}$ & 7 & $115.4_{ \pm 1.96}$ \\
\hline " & III & 7 & $123.4_{ \pm 1.14}$ & 0 & - \\
\hline Kitami- & Ainu & 24 & $121.8_{ \pm 0.84}$ & 15 & $114.6_{ \pm 0.98}$ \\
\hline
\end{tabular}

Table 28. Mandibular Breadth Index.

\begin{tabular}{|c|c|c|c|c|c|}
\hline & \multicolumn{2}{|r|}{$\hat{\delta}$} & \multicolumn{2}{|r|}{ 우 } \\
\hline & & n & $\mathrm{M} \pm \mathrm{E}(\mathrm{M})$ & n & $M \pm E(M)$ \\
\hline Moyoro & I & 22 & $89.0_{ \pm 0.68}$ & 5 & $89.9_{ \pm 1.26}$ \\
\hline$"$ & II & 8 & $87.8_{ \pm 0.80}$ & 7 & 87. $9_{ \pm 1.41}$ \\
\hline , & III & 7 & $84.8_{ \pm 0.74}$ & 0 & - \\
\hline Kitami & Ainu & 24 & $84.3_{ \pm 0.58}$ & 15 & 83. $2_{ \pm 0.62}$ \\
\hline
\end{tabular}


a significant difference between the first group and the latter two. Accordingly, the Maxillo-Alveolar Index (M a r t i n, 61/60) (Table 25) is in the first group the largest of all with a significant defference against the third group and the Kitami Ainu. It is noteworthy that the alveolar part of the maxilla of the first group is considerably broad and mighty in comparison with the third group and the Kitami Ainu.

5. Taking a view of the mandible, in both of the Intercondylar Breadth (Martin, No. 65) (Table 26) and the Bigonial Breadth (M a r t i n, No. 66) (Table 27), the first group has the largest breadth, the second group has the less larger, and the third group and the Kitami Ainu have the smallest of all. In the Mandibular Breadth Index (M a r i n, 66/65) (Table 28), the first group is the largest, the second group is slightly less larger and the the third group and the Kitami Ainu are the smallest of all. It is noted morphologically that the angle of the mandible of the first group displays a slight

Table 29. Ramus Height.

\begin{tabular}{|c|c|c|c|c|c|}
\hline & \multicolumn{2}{|r|}{$\delta$} & \multicolumn{2}{|r|}{ 우 } \\
\hline & & $\mathrm{n}$ & $\mathrm{M} \pm \mathrm{E}(\mathrm{M})$ & $\mathrm{n}$ & $\mathrm{M} \pm \mathrm{E}(\mathbf{M})$ \\
\hline Moyoro & I & 24 & 58. $7_{ \pm 0.69}$ & 9 & $52.3_{ \pm 1.01}$ \\
\hline$"$ & II & 14 & $56.7_{ \pm 0.75}$ & 12 & $52.9_{ \pm 0.88}$ \\
\hline & III & 7 & $57.4_{ \pm 1.04}$ & 0 & - \\
\hline Kitami- & Ainu & 24 & $57.3_{ \pm 0.61}$ & 17 & $51.7_{ \pm 0.52}$ \\
\hline
\end{tabular}

Table 31. Ramus Index.

\begin{tabular}{|c|c|c|c|c|c|}
\hline & \multicolumn{2}{|r|}{ 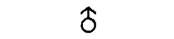 } & \multicolumn{2}{|r|}{ 우 } \\
\hline & & $\mathbf{n}$ & $M \pm E(M)$ & $\mathrm{n}$ & $M \pm E(M)$ \\
\hline Moyoro & $I$ & 24 & $72.0_{ \pm 0.53}$ & 9 & $78.8_{ \pm 0.89}$ \\
\hline " & II & 14 & $72.4_{ \pm 1.39}$ & 12 & $72.8_{ \pm 0.63}$ \\
\hline & III & 6 & $67.8_{ \pm 1.01}$ & 0 & - \\
\hline Kitami- & Ainu & 24 & $65.3_{ \pm 0.87}$ & 17 & $68.1_{ \pm 0.86}$ \\
\hline
\end{tabular}

Table 30. Ramus Breadth.

\begin{tabular}{|c|c|c|c|c|c|}
\hline & \multicolumn{2}{|r|}{ ऽ } & \multicolumn{2}{|r|}{ 우 } \\
\hline & & $\mathrm{n}$ & $\mathrm{M} \pm \mathrm{E}(\mathrm{M})$ & $\mathrm{n}$ & $\mathrm{M} \pm \mathrm{E}(\mathrm{M})$ \\
\hline Moyoro & I & 24 & $41.8_{ \pm 0.4^{\prime}}$ & 9 & $40.1_{ \pm 0.61}$ \\
\hline$"$ & II & 14 & $40.6_{ \pm 0.52}$ & 12 & 38. $3_{ \pm 0.39}$ \\
\hline , & III & 6 & $39.3_{ \pm 0.79}$ & 0 & - \\
\hline Kitami- & Ainu & 24 & $37.5_{ \pm 0.43}$ & 17 & $35.1_{ \pm 0.38}$ \\
\hline
\end{tabular}

tendency to turn over outwards, while in the third group and the Kitami Ainu such a tendency can be hardly observed.

With regard to the ramus of the mandible, in the Ramus Height (M a r i n, No. 70) (Table 29) no distinct difference can be observed among the four groups.

However, the Ramus Breadth (Marti n, No. 71) (Table 30) is the largest in the first group, larger in the second and the third group, and the smallest in the Kitami Ainu. The Ramus Index (M a r t i n, 71/70) (Table 31) is larger in the first and the second group, while less larger in the third group and the Kitami Ainu, with a significant difference between the former and the latter. Generally, the 
Ainu shows the larger ramus index among the various kinds of races. Accordingly it is noteworthy that the first group has the remarkably larger ramus index.

\section{Results}

Out of the human bones excavated from the Moyoro Shell Heap, the skulls were classified into three groups, such as, the first group, the second group, the third group accordingly to the originated stratum. Then the anthropological measurements were taken on the skulls as well as on the modern Kitami Ainu skulls in order to make a comparative study on the four groups. The following results were obtained:

1. The skulls from the profound stratum, the first group, belong to the early stage of the Moyoro Shell Heap formation. The main characteristics of this group are as follows: the neurocranium which owns a greater circumference is brachycephalic and also hypsicephalic and the splanchnocranium which owns the remarkably larger breadth and height is mesoprosope. The orbit is comparatively high mesoconche. The nose is mesorrhine close to leptorrhine. The alveolar part of the maxilla is broad and mighty, so that the mandible is also larger. The ramus of the mandible is extremely broad and accordingly the index is exceptionally large.

2. The skulls of the second group from the less profound stratum than the above are considered to be buried in the period of the Moyoro Shell Heap formation and make various kinds of differences in comparison with the first group. The main characteristics of the second group are as follows: the neurocranium is mesocephalic on account of the decrease of the Maximum Breadth, the splanchnocranium is mesoprosope, but both of the breadth and the hight are smaller. The orbital height is also ramarkably smaller, being middle-graded mesoconche. The nasal index is changing from the below border to the upper border of the mesorrhine type, owing to the decrease of the nasal height. The maxilloalvelar index decreases distinctly because of the decreasing breadth. In other words the alveolar part grows weaker than in the first group. The mandible as a whole remarkably loses the broadness. The ramus of the mandible seems to grow narrower.

3. The skulls of the third group which is thought to belong to the period after the end of the Moyoro Shell Heap formation show a few of remarkable differences against those of the first group. 
The neurocranium grows dolichocephalic and also orthocephalic owing to the decrease of the Maximum Breadth and of the BasionBregma Height. The circumference seems to show a decrease. The splanchnocranium becomes euryprosope on account of the decreasing facial breadth and remarkably decreasing facial height. The alveolar part of the maxilla loses the breadth, resulting in the decrease of the index. The mandible as a whole loses the breadth, especially the bigonial breadth, which causes the distinct decrease of the mandibular breadth index. The ramus breadth shows a decrease, which causes a decrease of the ramus index.

4. A comparative study between the first group of the Moyoro. Shell Heap Man and the Kitami Ainu reveals that, morphologically, the former is entirely different from the latter in some important points. However, it is almost impossible to find out the remarkable differences between the third group and the Kitami Ainu. The second group is thought to possess the intermediate form between the first and the third group.

5. The form of the first group skull is considered to change into that of the third group skull through that of the second group skull with the transition of the age, but the changing grades are suspected to be extremely strong for the gradual changes of one definite race in one definte area of the Moyoro Shell Heap. The term of the formation of the Moyoro Shell Heap being estimated during about 300 years, the changes of the type of the skull from the brachycephalic type to the dolichocephalic through the mesocephalic is too remarkable for the morphologically fairly stabilized skull. In addition to that, it is generally believed that the neurocranium shows a tendency to the brachycephalization, so that it is almost impossible to believe that the contrary phenomenon is supposed to take place in such a short time. The changes of the size of the splanchnocranium and those of the shapes of the orbit, the nasal part and the mandible arē also considerably distinct.

No significant, morphological differences are observed between the skull of the third group and that of the Kitami Ainu. If the close relationship between the above mentioned two might exist, this relationship is thought to be born several hundred years ago already and to be brought about to the modern age without the remarkable fluctuations.

6. Based on the above mentioned, the following reasoning may be adequate to the causes of the changes of the skulls of the Moyoro Shell Heap Man according to the stratum to which they belong. 
The so-called Moyoro Shell Heap Man who was absolutely different from the Ainu was thought to settle down in the Moyoro Area about 1000 years ago. In those days the ancestors of the Ainu wer: thought to inhabit in the vicinity of the Moyoro Area in the Kitaini province. By the mixture between these two races, the first group was thought to change into the second group, which was thought to turn out to be the third group. And the third group was thought to finally become the part of the Kitami Ainu.

\section{References}

1. It o, S.: On the skulls of the Moyoro Shell Heap Man, The 53th Japanese Anatomical Congress (1948), Acta Anatomica Nipponica, vol. 24 (1948). (Japanese)

2. Kodama, S.: The Moyoro Shell Heap (1948). (Japanese) 